Núm. 40, pp. 127-135 México, 2015

DOI: $10.18387 /$ polibotanica.40.8

\title{
RESPUESTA RIZOGÉNICA EN PINUS MAXIMARTINEZII RZEDOWSKI
}

\section{RHIZOGENIC RESPONSE OF PINUS MAXIMARTINEZII RZEDOWSKI}

\author{
M.C. Ojeda-Zacarías' ${ }^{1}$ L. Iracheta-Donjuan², P. López-Gómez², \\ F. Zavala-García ${ }^{1}$, y E.A. García-Zambrano ${ }^{1}$ \\ ${ }^{1}$ Universidad Autónoma de Nuevo León, Campus de Ciencias Agropecuarias, Facultad \\ de Agronomía, Francisco Villa s/n, colonia ExHacienda El Canadá, 66054 Escobedo, \\ Nuevo León. México. ${ }^{2}$ Instituto Nacional Investigaciones Forestales, Agrícolas y \\ Pecuarias, Campo Experimental Rosario Izapa, Km. 18 de la Carretera Tapachula a \\ Cacahoatan, 30870 Tuxtla Chico, Chiapas, México. \\ Correo electrónico: ojedacz@yahoo.com.mx
}

\section{RESUMEN}

El piñón azul o maxi piñón Pinus maximartinezii Rzedowski es una especie endémica en peligro de extinción debido a la alteración de sus poblaciones en su hábitat natural y que ha sobrevivido a una restricción genética extrema, además es considerado el más raro de los pinos piñoneros. En este trabajo se evaluó la respuesta rizogénica de brotes de Pinus maximartinezii, obtenidos a partir de embriones cigóticos regenerado vía organogénesis, los cuales se sometieron a tratamientos de enraizamiento in vitro. La mayor respuesta de enraizamiento se presentó con pulso de $24 \mathrm{~h}$ en presencia de $2.0 \mathrm{mg} \mathrm{L}^{-1}$ de IBA en los medios de cultivo DCR, GD y MS, al 100 y $50 \%$ de su concentración original más $0.5 \%$ de carbón activado por $\mathrm{L}^{-1}$. Después de ocho semanas se evaluó la variable conforme al número de brotes con raíces, la prueba de $\mathrm{X}^{2}$ mostró que el enraizamiento es independiente de los medios de cultivo así como la concentración de los mismos y dependiente al tiempos de pulso. La formación de raíces obtenidas en los brotes permite proponer esta especie con capacidad para ser propagada in vitro.
Palabras clave: brotes, enraizamiento, in vitro, Pinus maximartinezii.

\section{ABSTRACT}

Pinus maximartinezii Rzedowski is an endemic specie in danger of extinction due to population alteration in the wild and has survived extreme genetic restriction, it is also considered the rarest of pines. In this study rhizogenic response of Pinus maximartinezii sprouts, obtained from zygotic embryos regenerated via organogenesis subjected to in vitro rooting treatments was evaluated. The highest rooting response was obtained with a pulse of $24 \mathrm{~h}$ in the presence of $2.0 \mathrm{mg} \mathrm{L}^{-1}$ of IBA in DCR, GD and MS culture media at 100 and $50 \%$ of its original concentration plus $0.5 \%$ activated carbon per $\mathrm{L}^{-1}$. Number of shoots with roots was evaluated after eight weeks, the $\mathrm{X}^{2}$ test showed that rooting is independent of culture media, concentration and dependent to the pulse times. Root formation in shoots, allow us to propose this species to be propagated in vitro.

Key words: buds, rooting, in vitro, Pinus maximartinezii. 


\section{INTRODUCCIÓN}

México es uno de los países con más recursos forestales a nivel mundial, sus bosques, selvas y otras áreas con vegetación natural ocupan aproximadamente $74 \%$ del territorio nacional con $1461000 \mathrm{~km}^{2}$, de los cuales 700000 corresponden a bosques y selvas, los bosques son muy importantes en la economía mundial para el mantenimiento y preservación de nuevos ecosistemas (Altman, 2003). La productividad de las plantaciones forestales es esencial para satisfacer las demandas de productos maderables y así preservar las poblaciones naturales y la biodiversidad (Nehra, 2005). Se reportan ocho géneros de la familia de las pináceas y el de más amplia distribución es el género Pinus (Martínez, 1963). A este género pertenece $P$. maximartinezii o pino azul que es una especie endémica y en "peligro de extinción" según la NOM-059-SEMARNAT-2010. El ecosistema de esta especie se localiza en el cerro Piñones en extremo sur de la sierra Morones en Zacatecas, México (Rzedowski, 1978). Las pináceas endémicas son un elemento menor en la flora de México (López-Mata, 2001).

Tradicionalmente las Pináceas son propagadas a partir de semillas, estacas, injertos y fascículos enraizados (Go et al., 1993). El método más ampliamente usado para la producción de coníferas es la producción de plántulas a partir de semillas, sin embargo los individuos resultantes presentan una gran variabilidad, dificultando con ello la replicación de las características deseables del material original (Germain et al., 1975; Hartman y Kester, 1987). Por esta razón, los programas de mejoramiento genético en especies forestales se complica, entre otras cosas por sus largos ciclos biológicos de crecimiento lento y floración tardía, la fuerte influencia de los procesos de maduración y las pobres correlaciones de los caracteres entre individuos jóvenes y adultos (Toribio, 2001). El beneficio práctico de la propagación vegetativa-clonación, sólo será posible cuando se disponga de metodologías eficaces que permitan la multiplicación de individuos en fase madura de desarrollo (Bonga y Von Aderkas, 1993). En árboles el término madurez se refiere a los procesos asociados a la edad y que influyen en los cambios de desarrollo del individuo, afectando negativamente su capacidad regenerativa vía sexual (Fraga et al., 2002, Borja et al., 2004). El concepto de madurez tiene relevancia en cualquier programa de mejoramiento genético, tanto en el esquema de reproducción sexual como asexual, los procesos de envejecimiento dificultan el enraizamiento del material seleccionado para la continuidad del ciclo, hecho que ha sido demostrado para coníferas de alta importancia económica tales como Pinus radiata D. Don, Pinus taeda L., Pseudotsuga menziesii (Mirb.) Franco, Picea abies L. Karst, entre otras (Gutiérrez 1995, Von Aderkas y Bonga 2000, Prehn et al., 2003). Una de las herramientas de la biotecnología vegetal es el cultivo in vitro de plantas, conocido como cultivo de tejidos vegetales (De Filippis, 2014), éste se utiliza principalmente en estudios celulares y con fines de propagación clonal. El género Pinus ha sido clasificado como recalcitrante en relación con la formación de raíces in vitro al regenerar plantas por organogénesis. La fuerte influencia del cambio de fase (ciclófisis y topófisis), que se traduce en la recalcitración a las respuestas in vivo e in vitro según (Zobel y Talbert, 1984). Muchos trabajos realizados con el objeto de formar raíces in vitro en pinos, han descrito el empleo de diversos tratamientos 
con reguladores de crecimiento, variando las concentraciones de nutrientes inorgánicos, evaluando la influencia del estado físico del medio de cultivo e incluso la concentración de carbón activado en el medio de cultivo (Thorpe, 2004). Es por esta razón que en años recientes se ha optado por técnicas de cultivo de tejidos para mejorar los procesos de reproducción y multiplicación de genotipos nativos que por su naturaleza se comportan como recalcitrantes. El cultivo de tejidos trabaja con porciones pequeñas de tejido que permiten el estudio y manipulación del metabolismo vegetal (Sánchez-Olate et al., 2005). Mediante ésta técnica, se han logrado propagar más de 50 especies del género Pinus, utilizando embriones cigóticos como fuente de inóculo (Thorpe, 1990). Los inóculos (explantes) son multiplicados in vitro rápidamente y esto resulta en la producción de plantas que muchas veces alcanzan varios miles después de un año (Hargreaves et al., 2002). Por lo tanto, estás técnicas representan un método alternativo para propagar y conservar tejidos de plantas amenazadas o en peligro de extinción (Charls y Pence, 2004) como en el caso de P. maximartinezii que es una especie originaria de México, considerada en peligro de extinción debido a la alteración de sus poblaciones en su hábitat natural y su distribución geográfica restringida.

En este trabajo se evaluó la respuesta rizogénica de brotes de Pinus maximartinezii, obtenidos a partir de embriones cigóticos regenerados vía organogénesis, los cuales se sometieron a tratamientos de enraizamiento in vitro con la finalidad de buscar una alternativa de regeneración de la especie.

\section{MATERIAL Y MÉTODOS}

El presente trabajo de investigación se realizó en el Laboratorio de Biotecnología Vegetal de la Facultad de Agronomía de la Universidad Autónoma de Nuevo León, ubicado en carretera Zuazua-Marín Km. 17.5 Marín, Nuevo León, México.

Se utilizaron semillas maduras de 2.0 a $2.5 \mathrm{~cm}$ de largo en promedio colectadas en su hábitat natural de un árbol élite en producción del cerro Piñones. Los brotes que se utilizaron en los experimentos fueron regenerados a través de los megagametofitos extraídos de embriones cigóticos cultivados in vitro durante ocho semanas, antes de establecerlos en los medios de enraizamiento se establecieron en agua-agar mas $1.0 \mathrm{mg}$ $\mathrm{L}^{-1}$ de carbón activado durante dos semanas, con la finalidad de que se absolvieran los residuos de reguladores de crecimiento de la etapa de multiplicación y no influyeran en los tratamientos posteriores. Se realizó una clasificación previa según la altura del brote, se formaron tres grupos con la finalidad de demostrar si el tamaño del brote influía en la supervivencia y en el número de raíces, después del tratamiento con auxinas: el primer grupo formado por aquellos con una longitud menor a $1.0 \mathrm{~cm}$, el segundo con longitud mayor a $1.0 \mathrm{~cm}$ y el tercer grupo los que tenían una longitud mayor a $2.0 \mathrm{~cm}$.

\section{Enraizamiento de brotes in vitro}

Se reporta que la auxina que más se utiliza es el IBA en concentraciones de 0.1 a 10 mg L ${ }^{-1}$; o bien el someter los tejidos a altas concentraciones de auxinas por varias horas (pulso) y en ocasiones la combinación de algunas citocininas (Kin, Zeatina, BAP) a razón de 0.01-0.1 $\mathrm{mg} \mathrm{L}^{-1}$, benefician la 
formación de raíces (Villalobos et al., 1983; Thorpe, 2004). En esta investigación se establecieron tres experimentos. El primero consistió en someter los brotes del primer grupo en una solución por pulso en condiciones asépticas que contenía $1.0 \mathrm{mg} \mathrm{L}^{-1}$ IBA, $0.5 \mathrm{mg} \mathrm{L}^{-1}$ de ANA y pH 4.5 en estas condiciones las bases de los brotes permanecieron por $16 \mathrm{~h}$. Concluido este proceso, los brotes tratados fueron colocados en tres medios de cultivo básicos con la finalidad de probar si influía la concentración de las sales en la estimulación de raíces (Gupta y Durzan, 1985) DCR, (Gresshoff y Doy, 1972) GD, (Murashige y Skoog, 1962) MS a $50 \%$ de su concentración original de sales minerales así como de la sacarosa para los medios DCR y MS la sacarosa básica se utiliza en $30 \mathrm{~g} \mathrm{~L}^{-1}$ mientras que en medio GD $20 \mathrm{~g} \mathrm{~L}^{-1}$. Estos medios fueron preparados en dos modalidades en estado líquido y sólido a razón de $4 \mathrm{~g} \mathrm{~L}^{-1}$ de phytagel. Se establecieron 15 repeticiones por tratamiento en tubos de ensaye individualmente y posteriormente se colocaron en condiciones controladas de fotoperiodo de $16 \mathrm{~h}$-luz a $100 \mu \mathrm{mol} \cdot \mathrm{m}^{2} . \mathrm{S}^{-1}$ y temperatura de $24^{\circ} \mathrm{C}, \pm 2^{\circ} \mathrm{C}$ durante ocho semanas. Las unidades experimentales se establecieron bajo un diseño completamente al azar donde la variable a evaluar fue el número de brotes que lograron emitir raíces en la base de sus brotes.

Se estableció un segundo experimento utilizando los brotes del grupo dos el cual consistió en utilizar nuevamente los tres medios de cultivo semisólidos nuevamente usando phytagel a razón de $4.0 \mathrm{~g} \mathrm{~L}^{-1}$ en (DCR, GD, MS) a 75,50 y $25 \%$ de su concentración original de sales minerales y disminuyendo la sacarosa al 50\%, para los medios DCR y MS la concentración básica de sacarosa se reporta en $30 \mathrm{~g} \mathrm{~L}^{-1}$ mientras que en medio GD $20 \mathrm{~g} \mathrm{~L}^{-1}$. Los brotes fueron sometidos asépticamente a un proceso de pulso el cual consistió en colocar la parte basal de los brotes a una solución saturada de $10 \mathrm{mg} \mathrm{L}^{-1}$ de IBA por un lapso de $72 \mathrm{~h}$. Posteriormente, los brotes fueron depositados en tubos de ensaye las unidades experimentales fueron incubadas en condiciones controladas de fotoperiodo, temperatura y tiempo de incubación iguales al experimento anterior. El diseño experimental fue un completamente al azar con arreglo factorial $3 \times 3$ con ocho repeticiones por tratamiento. La variable evaluada fue: número de brotes que formaron raíces considerando el tamaño del brote y numero de raíces, además la elongación de éstas.

En un tercer experimento se utilizaron los brotes del grupo tres mayores a $2.0 \mathrm{~cm}$ de longitud éstos fueron colocados en un tratamiento de pulso de $2.0 \mathrm{mg} \mathrm{L}^{-1}$ de IBA a diferentes tiempos de exposición; 6,12 y $24 \mathrm{~h}$; posteriormente fueron colocados únicamente en dos medios de cultivo (DCR y GD) a $100 \%$ y $50 \%$ de su concentración de sus sales minerales, sin reguladores de crecimiento, y disminuyendo la concentración a $50 \%$ de sacarosa más la adición de $0.5 \%$ de carbón activado. En estas condiciones permanecieron en incubación por ocho semanas en condiciones controladas iguales a las de los dos experimentos anteriores. Los tratamientos fueron establecidos al azar regidos por un factorial, $3 \times 2 \times 2$ con ocho repeticiones por tratamiento, donde el factor A: son las horas al pulso, factor B: medios de cultivo y factor $\mathrm{C}$ : concentración de las sales, la variable evaluada fue número de brotes con raíz y número de raíces por brote considerando el tamaño del brote y elongación de raíces. 


\section{RESULTADOS Y DISCUSIÓN}

De acuerdo con George et al. (2008), las auxinas en cultivo de tejidos participan en la diferenciación de brotes y raíces además estimulan la división celular. Tiwari et al. (2002) mencionan que el enraizamiento in vitro es reemplazado por la aplicación de impulsos fisiológicos consistentes en la inmersión temporal de la parte basal de los brotes micropropagados a una solución de auxinas. Sin embargo algunas especies pueden formar raíces sin la aplicación exógena de auxinas como en Pinus banksiana y Pinus pinea (Harry y Thorpe, 1994; González et al., 1998). Pero también, existen casos que pueden llegar a tener raíces en presencia de estos reguladores de crecimiento como en Pinus nigra (López et al., 1996) y se reportan aquellos que a pesar de ser tratados con niveles altos en la concentración con auxinas forman un bajo porcentaje de raíces (Villalobos-Amador et al., 2002). Por su parte, Oliveira et al. (2003) no obtuvieron éxito en el desarrollo de raíces al utilizar tratamientos de pulso. En el experimento uno de esta investigación no fue posible analizar estadísticamente los resultados de los brotes después de ocho semanas de cultivo in vitro, debido que los brotes mantenidos tanto en medio líquido como sólidos, se oxidaron hasta llegar a la senescencia total, esto pudo estar relacionado con el tamaño de los brotes que no favoreció la inmersión temporal de la parte basal del brote en la solución de las auxinas. Sánchez-Cuevas y Salaverrio (2004) mencionan que la oxidación se puede atribuir comúnmente al exceso de fenoles presentes en el metabolismo de oxidación de los tejidos vegetales.

En el segundo experimento los brotes establecidos tendieron a formar callos en la base de los mismos pero continuaron su crecimiento y no existió oxidación ni senescencia después de ocho semanas, esta formación de callo pudo estar influenciada con la concentración, tiempo de exposición y tipo de auxinas utilizadas en el pulso. Aunque no existió diferencia significativa para ningún factor evaluado horas al pulso, medios de cultivo y concentraciones de las sales minerales. Esta respuesta coincide con lo mencionado por Capuana (2001), quien trabajando con Pinus cembra y Pinus pinea fue difícil de obtener enraizamiento.

Con respecto al tercer experimento, después de ocho semanas de cultivo se observa que la mayoría de los brotes no formaron raíces. La primera respuesta fue considerando las sales básicas de los medios de cultivo DCR y GD en cuanto al número de raíces formadas no existió diferencia significativa (tabla 1). Por otro lado, se determinó la concentración de las sales básicas de los medios de cultivo lo cual no contribuyó en mejorar el enraizamiento. Con respecto a las dos concentración de los medios nuevamente no existió diferencia significativa en cuanto al número de brotes con raíces (tabla 2 ) aunque se tienen antecedentes en otras coníferas que al disminuir la concentración de las sales básicas se logra obtener el enraizamiento tal es el caso de (Chin Yi et al., 1991) en brotes de Picea rubens estos fueron sometidos a un tratamiento de pulso IBA/NAA. $17 \%$ de los brotes formaron raíces después del tratamiento con $0.1 \mathrm{mM}$ IAA $+0.1 \mathrm{mM}$ IBA por $24 \mathrm{~h}$; y solo el $11 \%$ se obtuvo con $2.5 \mathrm{mM}$ IBA +2.5 mM NAA. El tratamiento más efectivo para enraizamiento fue el de $4 \mathrm{~h}$ de pulso en $1.0 \mathrm{mM} \mathrm{IBA}+10 \mathrm{mM}$ NAA a un $\mathrm{pH}$ de 4.5 , en el medio GD al $50 \%$ de su concentración; sacarosa $1-2 \%$ y $0.3 \%$ gelrite. Con respecto al factor tiempos de pulso, 
Tabla 1. Número de brotes de Pinus maximartinezii sin raíz, con una raíz y con dos raíces en los medios DCR y GD.

\begin{tabular}{ccccc}
\hline Medios & Sin raíz & Con una raíz & Con dos raíces & Total \\
\hline DCR & 38 & 8 & 2 & 48 \\
GD & 41 & 6 & 1 & 48 \\
Total & 79 & 14 & 3 & 96 \\
\hline
\end{tabular}

Tabla 2. Número de brotes de Pinus maximartinezii sin raíz, con una raíz y con dos raíces en las concentraciones de sales minerales.

\begin{tabular}{ccccc}
\hline Concentración & Sin raíz & Con una raíz & Con dos raíces & Total \\
\hline $100 \%$ & 42 & 5 & 1 & 48 \\
$50 \%$ & 37 & 9 & 2 & 48 \\
Total & 79 & 14 & 3 & 96 \\
\hline
\end{tabular}

únicamente tres brotes formaron una raíz en los tiempos de $6 \mathrm{~h}$ y $12 \mathrm{~h}$; mientras que, el tratamiento de $24 \mathrm{~h}$ presentó ocho brotes con una raíz y tres con dos raíces (tabla 3 ). Esto indica que el tiempo de pulso puede ser un factor determinante en la diferenciación de raíces además el tamaño de brote puede estar relacionado con esta respuesta.

\section{CONCLUSIONES Y RECOMENDACIONES}

El tratamiento de pulso con AIB por $24 \mathrm{~h}$ resultó con mayor número de brotes con raíz en comparación con el pulso a 12 y $6 \mathrm{~h}$ para la fase de enraizamiento in vitro. Sin embargo, para optimizar el enraizamiento se recomienda hacer modificaciones específicas a los tratamientos utilizados ya que deben ser investigados sus requerimientos para mejorar el porcentaje de respuesta de los brotes establecidos in vitro, además el resultado obtenido pudo estar influenciado por el tamaño de los brotes que fueron de al menos $2.0 \mathrm{~cm}$ de altura.

En el tercer experimento se demostró que el enraizamiento es independiente del medio

Tabla 3. Número de brotes de Pinus maximartinezii sin raíz, con una raíz y con dos raíces expuestos a tres tiempos de pulso.

\begin{tabular}{ccccc}
\hline Tiempo & Sin raíz & Con una raíz & Con dos raíces & Total \\
\hline $6 \mathrm{~h}$ & 29 & 3 & 0 & 32 \\
$12 \mathrm{~h}$ & 29 & 3 & 0 & 32 \\
$24 \mathrm{~h}$ & 21 & 8 & 3 & 32 \\
Total & 79 & 14 & 3 & 96 \\
\hline
\end{tabular}


de cultivo, la formación de raíces se obtuvo al incrementarse el tiempo de pulso. Esta respuesta podría indicar que el tiempo al pulso pudiera ser un factor importante en la emisión de raíces en los brotes de esta especie y el tamaño de los brotes pudiera ser un factor clave para el éxito del enraizamiento.

\section{LITERATURA CITADA}

Altman, A., 2003. "From plant tissue culture to biotechnology: Scientific revolutions, abiotic stress tolerance, and forestry". In Vitro Cellular \& Developmental Biology-Plant, 39: 75-84.

Bonga, J.M., y P. Von Aderkas, 1993. "Rejuvenation of Tissues from Mature Conifers and its Implications for Propagation in vitro". Clonal Forestry I, eds. Ahuja and Libby: Springer Berlin Heidelberg. pp. 182-199.

Borja, L.; M. Berdasco, M. Fraga, M. Cañal, R. Rodríguez, y C. Castresana, 2004. "A Pinus radiata AAA-ATPase, the expression of wish increases with tree ageing." Journal of Experimental Botany, 55: 1597-1599.

Capuana, M., 2001. "Cloning of Italian forest tree species by in vitro techniques". Ph.D. Dissertation. Belgium: University Gent. pp. 116.

Charls, S., y V. Pence, 2004. "In vitro propagation and acclimation of Avon Park harebells (Crotalaria avonensis), an endangered Florida species". In vitro cellular \& developmental biology-animal, 59: 2064.
Chin-Yi, L.; I.S. Harry, M.R. Thompson, y T.A. Thorpe, 1991. "Plantlet regeneration from cultured embryos and seedling parts of red spruce (Picea rubens Sorg)". Bot. Gaz, 152: 42-50.

De Filippis, L.F., 2014. “Crop Improvement Through Tissue Culture". Improvement of Crops in the Era of Climatic Changes. Eds. Ahmad, Wani, Azooz and Tran: Springer New York. pp. 289-346.

Fraga, M.F.; M.J. Cañal, y R. Rodríguez, 2002. "In vitro morphogenic potential of differently aged Pinus radiata trees correlates with polyamines and DNA methylation levels". Plant Cell, Tissue and Organ Culture, 70: 139-145.

Germain, E., J. Jalmat, y M. Marcheu, 1975. "Diversaspects de la biologieflorale du noyer". Le noyer, CTIFEL Paris. pp. 13-27.

George, E.F.; M.A. Hall, y G.J. De Klerk. 2008. "Micropropagation: Uses and Methods". Plant Propagation by Tissue Culture. Eds. George, Hall and De Klerk: Springer Netherlands. pp. 29-64.

Go, N.; G. Pérez-Orozeo, y S. Halos, 1993. "In vitro response of embryos from different provenances of Pinus caribaea var. hondurensis Morelet". Plant Cell, Tissue and Organ Culture, 32: 1-7.

González, M.V.; M. Rey, R. Tavazza, S. La Malfa, L. Cuozzo, y G. Ancora, 1998. "In vitro adventitious shoot formation on cotyledons of Pinus pinea". HortScience, 33: 749-750. 
Gresshoff, P.M., y C.H. Doy, 1972. "Development and differentiation of haploid Lycopersicon esculentum (tomato)". Planta, 107: 161-170.

Gupta, P.K., y D.J. Durzan, 1985. "Shoot multiplication from mature trees of Douglas-fir (Pseudotsuga menziesii) and sugar pine (Pinus lambertiana)". Plant Cell Reports, 4: 177-179.

Gutiérrez, B., 1995. “Consideraciones sobre la fisiología y el estado de madurez en el enraizamiento de estacas de especies forestales". Ciencia e Investigación Forestal, 9: 261-276.

Hargreaves, C.; L. Grace, y D. Holden, 2002. "Nurse culture for efficient recovery of cryopreserved Pinus radiata D. Don embryogenic cell lines". Plant Cell Reports, 21: 40-45.

Harry, I.S., y T.A. Thorpe, 1994. "Regeneration of plantlets through organogenesis from mature embryos of jack pine". Plant Cell, Tissue and Organ Culture, 37: 159-164.

Hartmann, H.T.; D.E. Kester, y A.M. Ambrosio, 1987. Propagación de plantas: principios y prácticas. México: Continental. pp. 760 .

López-Mata, L., 2001. "Proteins, amino acids and fatty acids composition of nuts from the Mexican endemic rarity, Pinus maximartinezii, and its conservation implications". Interciencia, 26: 606-610.

López, M.; J. Pacheco, R. Rodríguez y R. Ordás, 1996. "Regeneration of plants from isolated cotyledons of salgareño pine (Pinus nigra Arn. ssp. salzmannii (Dunal) Franco)". In Vitro Plant, 32: 109-114.

Martínez, M., 1963. Las pináceas mexicanas. $3^{\text {a }}$ ed. México: Universidad Nacional Autónoma de México. pp. 11-39.

Murashige, T., y F. Skoog. 1962. “A Revised Medium for Rapid Growth and Bio Assays with Tobacco Tissue Cultures". Physiologia Plantarum, 15: 473-497.

Nehra, N.S.; M.R. Becwar, W.H. Rottmann, L. Pearson, K. Chowdhury, S. Chang, H. Dayton Wilde, R.J. Kodrzycki, C. Zhang, K.C. Gause, D.W. Parks, y M.A. Hinchee, 2005. "Forest biotechnology: Innovative methods, emerging opportunities." In Vitro Cellular \& Developmental Biology-Plant, 41: 701-717.

NOM-059-ECOL-2010. Norma Oficial Mexicana. "Protección ambientalespecies nativas de México de flora y fauna silvestres- categorías de riesgo y especificaciones para su inclusión, exclusión o cambio - lista de especies en riesgo". Diario Oficial de la Federación, segunda sección, México, DF, pp. 1-77

Oliveira, P.; J. Barriga, C. Cavaleiro, A. Peixe, y A. Z. Potes, 2003. "Sustained in vitro root development obtained in Pinus pinea L. inoculated with ectomycorrhizal fungi”. Forestry, 76: 579-587.

Prehn, D.; C. Serrano, A. Mercado, C. Stange, L. Barrales, y P. Arce-John- 
son. 2003. "Regeneration of whole plants from apical meristems of Pinus radiata". Plant Cell, Tissue and Organ Culture, 73: 91-94.

Rzedowski, J., 1978. Los tipos de Vegetación de México. México: Limusa Wiley. pp. 285-313.

Sánchez-Cuevas, M., y J. L. Salaverría, 2004. "Control de la oxidación y la contaminación en el cultivo in vitro de fresa (Fragaria X ananassa Duch.)". Revista Científica UDO Agrícola, 4: 21-26.

Sánchez-Olate, M.E., D.G. Ríos Leal, y E. R.R., 2005. "La biotecnología vegetal y el mejoramiento genético de especies leñosas de interés forestal y sus proyecciones en Chile". Biotecnología vegetal en especies leñosas de interés forestal, Eds. Sánchez-Olate, y Ríos Leal. Chile: Facultad de Ciencias Forestales, Universidad de Concepción. pp. 162.

Thorpe, T.A., 2004. "Turning point article to root or not to root, that is the question: Reflections of a developmental plant physiologist." In Vitro Cellular \& Developmental Biology-Plant, 40: 128-142.

Thorpe, T.A., I.S. Harry, y P.P. Kumar, 1991. "Application of micropropagation to forestry". Micropropagation, eds. Debergh and Zimmerman: Springer Netherlands. pp. 311-336.
Tiwari, S.K.; K.P. Tiwari, y E.A. Siril, 2002. "An improved micropropagation protocol for teak". Plant Cell, Tissue and Organ Culture, 71: 1-6.

Toribio, M., 2001. "Application of biotechnological tools in the genetic breeding of forest species." Melhoramento, 37 : 148-160.

Villalobos-Amador, E.; G. Rodríguez-Hernández, y E. Pérez-Molphe-Balch. 2002. "Organogenesis and Agrobacterium rhizogenes-induced rooting in Pinus maximartinezii Rzedowski and P. pinceana Gordon". Plant Cell Reports, 20: 779-785.

Villalobos, V.M.; T.A. Thorpe, y E.C. Yeung, 1983. "Aplicaciones del cultivo de tejidos en especies forestales". México: Ciencia y Desarrollo, 51: 43-59.

Von Aderkas, P., y J.M. Bonga, 2000. "Influencing micropropagation and somatic embryogenesis in mature trees by manipulation of phase change, stress and culture environment". Tree Physiol, 20: 921-928.

Zobel, B., y J. Talbert, 1984. Applied forest tree improvement. John Wiley \& Sons., New York, pp. xv +505 pp.

Recibido: 8 febrero 2014. Aceptado: 23 enero 2015. 